\title{
Establecimiento de un método eficiente de germinación in vitro de arnaucho supano (Capsicum chinense Jacq.)
}

\section{Establishment of an efficient in vitro germination method of arnaucho supano (Capsicum chinense Jacq.)}

Julio Alcides Rojas Chávez', Brayan Anthony Lugo Chinchay ${ }^{1}$, Alexandra Jherina Pineda Lázaro', Giselle Jazmín Aguilar Balabarca', Alexis Argüelles Curaca ${ }^{1}$, Hermila Belba Díaz Pillasca ${ }^{1}$

\section{RESUMEN}

Objetivo: Establecer un método eficiente de germinación in vitro a partir de semillas de arnaucho supano (Capsicum chínense Jacq.). Materiales y Métodos: Las semillas de arnaucho supano fueron sometidas a desinfección con alcohol al $70 \%$ por 60 segundos y posterior a cinco concentraciones de hipoclorito de calcio $(0,5 \%, 1 \%, 1,5 \%, 2 \%$ y $2,5 \%$ de $\mathrm{NaClO})$, posterior a la desinfección se probaron seis tratamientos para el establecimiento y germinación in vitro de las semillas con diferencia en el porcentaje del medio de cultivo MS y niveles de pH. Resultados: Los mejores resultados en el proceso de desinfección fueron los tratamientos con $1,5 \%$ y $2 \%$ con $0 \%$ de contaminación y $0 \%$ de oxidación. Para el proceso de germinación no se mostraron diferencias significativas entre las concentraciones de medio de cultivo MS, pero si se presento un efecto por el nivel de 7,8 de pH, reduciendo la germinación y crecimiento de las plántulas de arnaucho in vitro. Conclusión: Se logró establecer un método eficiente de germinación in vitro a partir de semillas de arnaucho supano (Capsicum chínense Jacq.). Presentando un protocolo de desinfección optimo y considerando esta metodología como un método de conservación ex situ para posteriores trabajos de investigación.

Palabras claves: Arnaucho, supe, ají supano, Capsicum chínense, in vitro.

\section{ABSTRACT}

Objective: To establish an efficient in vitro germination method from arnaucho supano (Capsicum chínense Jacq.) Seeds. Materials and Methods: The arnaucho supano seeds were subjected to disinfection with $70 \%$ alcohol for 60 seconds and later at five concentrations of calcium hypochlorite $(0,5 \%, 1 \%, 1,5 \%, 2 \%$ and $2,5 \%$ of $\mathrm{NaClO})$, later After disinfection, six treatments were tested for the establishment and in vitro germination of the seeds with a difference in the percentage of the MS culture medium and $\mathrm{pH}$ levels. Results: The best results in the disinfection process were the treatments with $1.5 \%$ and $2 \%$ with $0 \%$ contamination and $0 \%$ oxidation. For the germination process, no significant differences were shown between the concentrations of the MS culture medium, but there was an effect due to the $\mathrm{pH}$ level of 7,8, reducing the germination and growth of the arnaucho seedlings in vitro. Conclusion: An efficient in vitro germination method was established from arnaucho supano seeds (Capsicum chínense Jacq.). Presenting an optimal disinfection protocol and considering this methodology as an ex situ conservation method for subsequent research work.

Keywords: Arnaucho, supe, chili supano, Capsicum chínense, in vitro.

\section{INTRODUCCIÓN}

El arnaucho (Capsicum chínense Jacq.) es una planta herbácea, que pertenece a la familia de las Solanáceas. Se originó en amazona y fue domesticado en diferentes partes del sur y centro américa (Palacios, 2011). A nivel mundial, el principal exportador de ajíes es México; siendo los Estados Unidos uno de los principales importadores de ajíes en el mundo. En el Perú, dentro de las variedades de Capsicum chínense Jacq. se encuentra el arnaucho; comúnmente cultivada en la costa norte (Jager, Jiménez y Amaya, 2013). La importancia del cultivo de arnaucho radica por la alta concentración de capsaicinoides, que contiene efectos antiinflamatorios (Ruiz et al., 2016). Dentro de los usos más relevantes del arnaucho en el ámbito de la salud, se emplea por sus propiedades antioxidante y prevención de cáncer (Zamora et al., 2018).

Los cultivos in situ de arnaucho suelen sembrarse en condiciones ambientales, pero a medida que aumenta la temperatura del ambiente suele descender la obtención de frutos en la planta. Existen microorganismos y plagas que suelen dañar el crecimiento y desarrollo del arnaucho que son comunes entre especies del género Capsicum (Hernández,
Pineda y Noriega-Córdova, 2019). La transferencia de diversas enfermedades sobre todo perjudica la producción de arnaucho. Entre las principales enfermedades se menciona la alternariosis, producido por hongos que alteran el rendimiento de la planta, por la aparición de manchas negras sobre la zona afectada. (Marín, 2012).

Los cultivos de arnauchos suelen cultivarse de forma vegetativa, a través de semillas con la ventaja de preservar sus características fenotípicas y genotípicas. De acuerdo a los estudios, los arnauchos presentan problemas de oxidación en sus pigmentos carotenoides. El efecto de oxidación permite que la planta pierda su capacidad colorante en sus frutos, por la ruptura de los enlaces dobles de la cadena carbonada de las moléculas de carotenoides (Perez, 2000). A nivel de los tallos, los arnauchos suelen ser recalcitrante; impidiendo la regeneración por cultivo in vitro de tejidos (Gomez, 2016). Debido a estos problemas se han hecho necesario encontrar nuevas opciones de propagación y aplicación de métodos innovadores como vienen siendo el cultivo in vitro de tejidos vegetales, las cuales permiten obtener plantas libres de microorganismos (Calva et al., 2005; Argüelles et al., 2020). Las técnicas de cultivo in vitro de tejidos vegetal son considerados como unas herramientas esenciales en la 
biotecnología vegetal para la propagación de arnaucho de interés agronómico con finalidad a futuro de mejoramiento genético. La importancia de los cultivos de tejidos vegetal en los frutales radica por su uso fácil en la propagación de plantas y creación de innovadoras fuentes de variabilidad genética (Valdés-Infantes et al., 2012).

Por lo tanto, el objetivo de la presente investigación fue establecer un método eficiente de germinación in vitro a partir de semillas de arnaucho supano (Capsicum chínense Jacq.).

\section{MATERIAL Y MÉTODOS}

\section{Material vegetal}

Se recolectaron frutos maduros de arnaucho supano (Capsicum chínense Jacq.) en campos de cultivo de la campiña de Supe, en la provincia de Barranca. Posteriormente fueron transportados al Laboratorio de Biotecnología Vegetal (LBV), perteneciente a la escuela profesional de Biología con mención en Biotecnología, facultad de Ciencias, Universidad Nacional José Faustino Sánchez Carrión (UNJFSC), Huacho, Huaura, Lima, Perú.

Se realizaron cortes a los frutos para poder extraer las semillas, las cuales serían empleados en el presente trabajo de investigación.

\section{Desinfección de semillas de arnaucho.}

Las semillas de arnaucho se lavaron con agua y detergente liquido para quitar rastros y partes aún del fruto, posteriormente fueron llevadas al equipo de cámara de flujo laminar, el equipo fue previamente esterilizado con luz ultravioleta durante 30 minutos donde además se encontraban los materiales de metal como pinzas y bisturís, necesario para el trabajo en condiciones asépticas.

En la cámara de flujo laminar se inicio con el proceso de desinfección de las semillas de arnaucho, primero se sumergieron las semillas en etanol al $70 \%$ durante un minuto y seguidamente se sumergieron en solución de hipoclorito de sodio $(\mathrm{NaClO})$ durante 10 y 15 minutos en agitación constante, para determinar la concentración adecuada de $\mathrm{NaClO}$ se realizo los siguientes tratamientos: $\mathrm{NC} 1: 0.5 \%$ de $\mathrm{NaClO}, \mathrm{NC} 2$ : $1 \%$ de $\mathrm{NaClO}, \mathrm{NC} 3: 15 \%$ de $\mathrm{NaClO}, \mathrm{NC} 4: 2 \%$ de $\mathrm{NaClO}$ y NC5: $2,5 \%$ de $\mathrm{NaClO}$. Seguidamente se continuo con tres lavados en agua destilada estéril, cada uno de los lavados se realizo durante 10 minutos. Posterior a los lavados se introdujeron tres semillas por cada tubo de ensayo con medio agar agua $(7 \mathrm{~g} / \mathrm{L}$ de agar agar).

Las semillas permanecieron en cámara de crecimiento con condiciones controladas $\left(25^{\circ} \mathrm{C}, 75 \%\right.$ humedad, fotos periodo 16 horas luz y 8 horas oscuridad, intensidad lumínica de 1500 lux) durante dos semanas para determinar el porcentaje de contaminación y oxidación.

\section{Establecimiento y germinación in vitro de semillas de} arnaucho.

Una vez establecido el protocolo de desinfección idóneo para el experimento se continuo con le proceso de establecimiento y germinación de las semillas de arnaucho en condiciones in vitro. Para lo cual se emplearon seis diferentes tratamientos con variantes en la concentración del medio de cultivo MS (Murashige y Skoog, 1962) y el pH de los respectivos medios (Tabla 1), adicionados con $17 \mathrm{~g} / \mathrm{L}$ de sacarosa como fuente de carbono y $7 \mathrm{~g} / \mathrm{L}$ de agar agar como agente gelificante, el $\mathrm{pH}$ del medio se ajusto a 5.8 antes de agregar el agente gelificante y se continuo con su esterilización en autoclave por 20 minutos a $121^{\circ} \mathrm{C}$ y 1,2 Bar de presión. El medio de cultivo MS estuvo compuesta por los micronutrientes, macronutrientes, fuentes de hierro y vitaminas establecidos por Murashige y Skoog (1962).

\section{Tabla 1}

Tratamientos de medios de cultivo para la germinación in vitro de arnaucho.

\begin{tabular}{ccc}
\hline TRATAMIETO & CONCENTRACIÓN MS $(\%)$ & $\mathrm{pH}$ \\
\hline T1 & 100 & 3,8 \\
T2 & 100 & 5,8 \\
T3 & 100 & 7,8 \\
T4 & 50 & 3,8 \\
T5 & 50 & 5,8 \\
T6 & 50 & 7,8 \\
\end{tabular}

En cada tubo de ensayo con los diferentes tratamientos de medio de cultivo se introdujeron tres semillas de arnaucho. Luego fueron colocados en cámara de crecimiento con condiciones controladas $\left(25^{\circ} \mathrm{C}, 75 \%\right.$ humedad, fotos periodo 16 horas luz y 8 horas oscuridad, intensidad lumínica de 1500 lux) durante cuatro semanas para determinar el porcentaje de semillas germinadas y altura de plantas.

\section{Diseño experimental y análisis estadístico}

Se empleó un diseño completamente al azar (DCA) con 15 repeticiones por tratamiento para el proceso de desinfección y DCA con arreglo factorial para el proceso de germinación in vitro. Las variables a evaluar en el proceso de desinfección de semillas fueron porcentaje de contaminación (\%) y porcentaje de oxidación (\%), datos que se obtuvieron trascurrida dos semanas posterior al establecimiento in vitro. Las variables a evaluar en el proceso de germinación in vitro fueron porcentaje de semillas germinadas (\%) y altura de plantas germinadas $(\mathrm{mm})$, datos que se obtuvieron trascurrida cuatro semanas posterior al establecimiento in vitro. Los datos se procesaron mediante Análisis de Varianza (ANVA) y la comparación entre las medias se realizó de acuerdo a la prueba de Tukey $(p \leq$ $0,05)$. Todos los análisis estadísticos fueron realizados mediante el paquete estadístico agricolae del software libre $R$ versión 3.6.2.

\section{RESULTADOS}

\section{Desinfección de semillas de arnaucho}

Los resultados relacionados con el porcentaje de porcentaje de contaminación (\%) y porcentaje de oxidación (\%) se reflejan en la Tabla 2. En relación al porcentaje de contaminación, se logró la desinfección de las semillas de arnaucho empleando diferentes concentraciones de hipoclorito de sodio, presentando los mejores resultados con el tratamiento NC3, 
NC4 y NC5, los cuales presentaron $0 \%$ de contaminación. Los mejores resultados en porcentaje de oxidación se obtuvieron con los tratamientos NC1, NC2, NC3 y NC4, con $0 \%$ de oxidación. Siendo los mejores resultados en términos de menores porcentajes de contaminación y oxidación los tratamientos NC3 y Nc4.

Tabla 2. Efecto del hipoclorito de sodio en la desinfección de semillas de arnaucho.

\begin{tabular}{cccc}
\hline TRATAMIENTO & NaCIO (\%) & CONTAMINACIÓN & OXIDACIÓN (\%) \\
\hline NC1 & 0,5 & $67 \mathrm{a}$ & $0 \mathrm{~b}$ \\
NC2 & 1 & $20 \mathrm{~b}$ & $0 \mathrm{~b}$ \\
NC3 & 1,5 & $0 \mathrm{c}$ & $0 \mathrm{~b}$ \\
NC4 & 2 & $0 \mathrm{c}$ & $0 \mathrm{~b}$ \\
Nc5 & 2,5 & $0 \mathrm{c}$ & $26 \mathrm{a}$ \\
\hline
\end{tabular}

Medias con letras distintas difieren significativamente según prueba de Tukey $(p<0,05)$.

\section{Establecimiento y germinación in vitro de semillas de arnaucho}

Se determino que no existía interacción entre las variables de concentración del medio MS y el nivel de $\mathrm{pH}$ en la germinación in vitro pero si existía interacción en la altura de las plantas germinadas in vitro (Figura 1), en efecto simples no se presente diferencia significativa entre la concentración de medio MS, para el efecto simple de nivel de $\mathrm{pH}$ si se presentaron diferencias significativas, debido a que con 7,8 de $\mathrm{pH}$ se reduce la germinación y crecimiento de las plántulas de arnaucho in vitro (Figura 2).

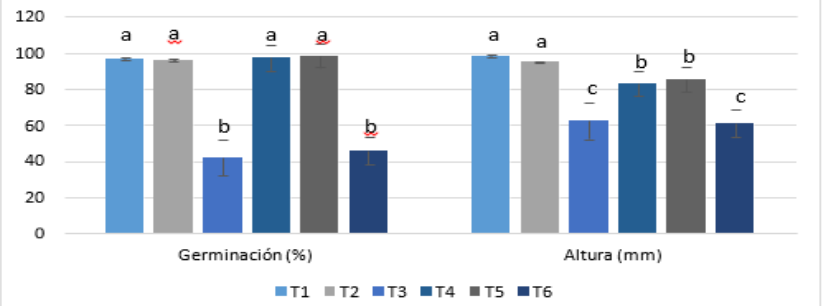

Figura 1. Porcentaje de germinación in vitro de arnaucho y altura $(\mathrm{mm})$. Medias con letras distintas difieren significativamente según prueba de Tukey $(p<0,05)$.

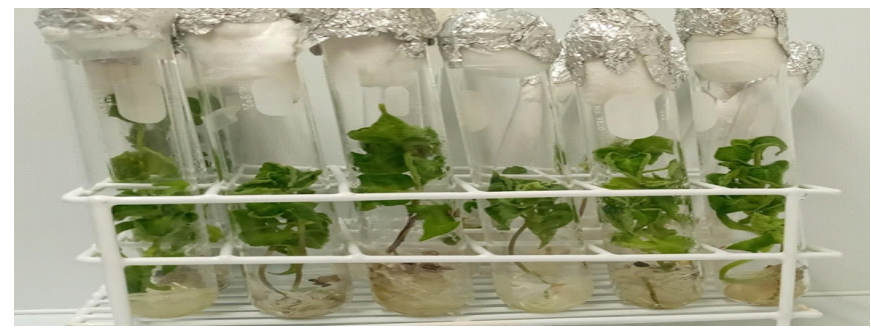

Figura 2. Plántulas de arnaucho germinadas en medio de cultivo MS a la mitad de su concentración.

\section{DISCUSIÓN}

El proceso de desinfección de las semillas de arnaucho fue importante de determinar debido a que en los estudios en condiciones in vitro es necesario mantener los cultivos limpios y libres de contaminantes (bacterias y hongos) que pueden competir con las plantas por los nutrientes presentes en el medio de cultivo, así mismo afectar a la planta de manera negativa perjudicando el estudio de las variables a determinar en la investigación (Fajardo, 2006).

Los principales contaminantes que se presentaron fueron por agentes fúngicos, eso esta relacionado con la presencia de esporas en el ambiente siendo muy necesario una optima esterilización de los materiales y previa desinfección del área de estudio, adicionalmente es crucial la capacitación de las personas que trabajaran en este tipo de condiciones para una optima manipulación y cuidado al momento de la manipulación de instrumentos y material vegetal. Das y Pal (2005) determinaron que el principal problema y limitante en el establecimiento en condiciones in vitro es por la presencia de contaminantes fúngicos viables.

Uno de los agentes desinfectantes de mayor uso en cultivo de tejidos es el $\mathrm{NaClO}$ por presentar buenos resultados en diferentes tipos de investigaciones en esta área, pero presenta una parte negativa en altas concentraciones y tiempos prolongados de exposición a los explantes, que pueden ocasionar la oxidación fenólica y por lo tanto reducir la sobrevivencia de estos explantes iniciales. Esto se pudo observar en los resultados en el tratamiento NC5, que se presento oxidación de las semillas de arnaucho tal como afirma George (1996), quien demostró que algunas especies liberan sustancias fenólicas acumuladas que se relacionan con inhibidores de crecimiento y que pueden también afectar presentando necrosis en los explantes.

El porcentaje de desinfección obtenida fue del 100\% tan como muestra la Tabla 1 empleando desde $1,5 \%$ de $\mathrm{NaClO}$ para semillas de arnaucho, estos resultados son similares a los obtenidos por Hernández, Pineda y Díaz (2019) en semillas de páprika (Capsicum annuum L.) cv. Papri King empleando la misma concentración de $\mathrm{NaClO}$, pero durante un menor tiempo de exposición de las semillas a la solución (10 minutos). De la misma manera Hernández et al (2020) y HernándezAmasifuen et al (2021), obtuvieron $100 \%$ de semillas libre de contaminación empleando $2 \%$ de $\mathrm{NaClO}$ durante 15 minutos en semillas de rocoto (Capsicum pubescens Ruiz \& Pav.). El porcentaje de germinación y la altura de plantas germinadas en condiciones in vitro que se obtuvieron en la presente investigación fueron similares a los obtenidos por Hernández et al (2019) en semillas de páprika (Capsicum annuum L.) cv. Papri King al obtener $97,8 \%$ de plantas germinadas empleando medio de cultivo MS al $100 \%$ de su concentración adicionando $1 \mathrm{mg} / \mathrm{L}$ de ácido giberelico para incrementar el porcentaje de germinación mientras que sin la adición de la hormona obtuvieron $71,1 \%$ de germinación, para el caso de las alturas de plantas los resultados que obtuvieron fueron superiores al presentar plántulas de $126 \mathrm{~mm}$ de altura a las cuatro semanas en medios de cultivo MS $100 \%$ de su concentración adicionado con $1 \mathrm{mg} / \mathrm{L}$ de ácido giberelico.

\section{CONCLUSIÓN}

En la presente investigación se logró establecer un método eficiente de germinación in vitro a partir de semillas de arnaucho supano (Capsicum chínense Jacq.). Presentando un protocolo de desinfección optimo con $0 \%$ de contaminación y $0 \%$ de oxidación de las semillas, y el método eficiente de 
germinación con $97 \%$ de semillas de arnaucho germinadas. Esto permite crear un antecedente de investigación en una especie que se encuentra en peligro de extinción, considerando esta metodología también relacionada como un método de conservación ex situ para posteriores trabajos de investigación.

\section{REFERENCIAS.}

Argüelles, A., Hernández, A., Cortez, A. y Díaz, H. 2020. Callogénesis in vitro de paprika (Capsicum annuum L.) cv. Papri King a partir de tallos. Big Bang Faustiniano 9(1): 4-7.

Calva, G. y Perez, J. 2005. Cultivo de celulas y tejidos vegetales: fuente de alimentos para el futuro. Revista Digital Universitaria, 6(11), 3-4. ISSN 1067-6079.

Das, M. y Pal, A. 2005. In vitro regeneration of Bambusa balcoa Roxb. Factors affecting changes of morphogenetic competence in axillary buds. Planta Cell Tissue and Organ Culture 81(1): 109-112.

Fajardo, L. 2006. Establecimiento in vitro de yemas axilares de Guada angustifolia Kunth. Tesis en Opción al Título de Master en Biotecnología Vegetal. IBP. UCLV. 80 pp.

George, E. 1996. Plant propagation by tissue culture. 2nd ed. Part 1. Exegenetics Ltd.

Gomez, L. 2016. Establecimiento de un protocolo para la induccion de la androgenesis en Capsicum chinense Jacq. Centro de Investigacion Cientifica de Yucatan,A.C. Mexico. pp. 1-2.

Hernández, A., Argüelles, A., Cortez, A., Díaz, H. 2020. Efecto de la concentración de 2,4-diclorofenoxiacético en la inducción de callos in vitro utilizando cotiledones de rocoto (Capsicum pubescens Ruiz \& Pav.). The Biologist 17(2): 327-334.

Hernández, A., Pineda, A., Díaz, H. 2019. Efecto de la luz y del ácido giberélico en la germinación in vitro de Capsicum annuum L. cv. 'Papri King'. Biotecnología Vegetal 19(3): 165-170.

Hernández, A., Pineda, A. y Noriega-Córdova, H. 2019. Aislamiento e identificación de Fusarium oxysporum obtenidos de zonas productoras de "ají paprika" Capsicum annumm L. (Solanaceae) en el distrito de Barranca, Perú. Arnaldoa 26(2): 689-698.
Hernández-Amasifuen, A.D., Argüelles-Curaca, A., CortezLázaro, A.A. y Díaz-Pillasca, H.B. 2021. In vitro induction of callus from foliar explants in rocoto (Capsicum pubescens Ruiz \& Pav.). La Granja: Revista de Ciencias de la Vida 33(1): 7-15.

Jager, M., Jiménez, A. y Amaya, K. 2013. Las cadenas de valor de los ajíes nativos de Perú. Compilación de los estudios realizados dentro del marco del proyecto "Rescate y Promoción de Ajíes Nativos en su Centro de Origen” para Perú. Bioversity International. Cali.

Marin, E. 2012. Embriogenesis somatica del genero capsicum: Validacion de un protocolo de regeneracion in vitro en Capsicum annuum. Centro de investigacion cientifica de Yucatan,A.C. 3-6p

Murashige, T. y Skoog, F. 1962. A Revised Medium for Rapid Growth and Bio Assays with Tobacco Tissue Cultures". Physiologia Plantarum. 15 (3): 473-497.

Palacios, E. 2011. Caracterización del efecto quimiotrópico del glutamato en raíces de chile habanero (Capsicum chínense Jacq.) Tesis de maestro en ciencias. Centro de Investigación Científica de Yucatán, A.C. Mérida, Yucatán, México. 5-6p.

Perez, A. 2000. Oxidacion de pigmentos carotenoides en funcion de su estructura y entorno lipidico. Universidad de Sevilla. Sevilla, España. pp. 2-3.

Ruiz, R., Nava, M., Landeros, C. y Díaz, G. 2016. Potencial productivo y limitantes para el cultivo del chile habanero Capsicum chinense Jacq. en el estado de Veracruz Mexico. RINDERESU, 1-7.

Valdés-Infante, J., Rodríguez, N., González, L., Velázquez, J., Rivero, D., Sourd, D., Martínez, F. y Rodríguez, J. 2012. La biotecnología como herramienta para la propagación, conservación y el mejoramiento genético del guayabo. Rev. Colomb. Biotecnol. 14(2): 8-9.

Zamora, L., Rodriguez, R., Garcia, L., Hernandez, J. y Hernandez, T. 2018. Estudio del pericarpio de chile habanero (Capsicum chinense Jacq.) por espectroscopia raman. Chilean J. Agric. Anim. Sci., 34(1), 68-74. 